\title{
The Impact of Contextual Factors on Response Patterns of Novel ${ }^{1}$ Word Pairings
}

\author{
Running head: Contextual Factors and Children's Word Pairings
}

\author{
Asimina M. Ralli \\ Department of Psychology, Faculty of Philosophy, Pedagogy, and Psychology, National and Kapodistrian University of Athens, \\ University Campus, Ilissia 15784, Athens, Greece
}

Copyright $\subset 2016$ by authors, all rights reserved. Authors agree that this article remains permanently open access under the terms of the Creative Commons Attribution License 4.0 International License

\begin{abstract}
The overall aim of the current study was to investigate the impact of task presentation and context of exposure on children's response patterns of novel word object pairings. The hypothesis was that children's responses will vary by task setting (instructions, number of choice items, and context of presentation). A set of three experiments was administered to 64 preschool age children. Markman's and Hutchinson's experimental paradigm was used to investigate our hypothesis. The results suggest that task presentation and context of exposure have an impact on children's response patterns of novel word object pairings, since the inferences about word pairings were highly sensitive to task demands. The results are discussed in terms of their applications both theoretically and methodologically.
\end{abstract}

Keywords Task Presentation, Word Pairings, Taxonomic, Thematic, Contextual Factors, Preschool Children

\section{Introduction}

One of the most crucial questions in language acquisition research, is how do children learn new words. Given the array of things a word could mean, how do they decide what a word means? Different theories on how children limit possible word meanings have been proposed. Many of the traditional theories focus on the learning mechanisms, suggesting that children rely on general inductive mechanisms to infer a word's meaning, while some more recent studies highlight also the importance of the learning context $[1,7,13,17,21,34,37]$. Therefore, one question that comes forward is which is the role of the learning context where the new words are presented, in order for the children to infer a word's meaning?

If we first look at the traditional proposed answers to the previous question, Markman and her colleagues [21] have argued that constraints or biases make the inductive problem solvable. Constraints should be thought of as "default assumptions, as probabilistic biases that provide good first guesses but not final solutions" [15, 37]. Markman and Hutchinson [21] proposed that young children limit the scope of a novel word to objects of "the same kind"- in other words to objects that belong in the same semantic category. The taxonomic constraint (also known as the taxonomic bias) leads children, when hearing a novel word, to shift their attention to categorical properties (e.g. items related categorically, such as two or more fruits), rather than to thematic properties (e.g. environmental associates, such as bird-nest, dog-bone) of objects. These rules out other associates of the originally named object as possible referents of the novel word [1, 13, 17, 21, 34].

However, the previous studies have incorporated subtle procedural details (e.g. instructions, forced choice tasks) which may have biased children to choose taxonomic pairings in the label condition. Additionally, it has been claimed, almost 15 years ago by Bloom [3] that experimental studies, usually assess word learning using artificial paradigms by asking children to choose two picture items, outside of a naturalistic context, ignoring the social and linguistic context in which the new words are usually introduced in everyday life. More contextualized research on word learning, which takes into account the contextual factors of the task presentation is needed in order to further investigate how children's responses can reflect their understanding of the experimental situation.

In Scott, Greenfield, \& Urbano's study [28] thematic (e.g., environmental associates such as bird-nest, dog-bone) and taxonomic relations (e.g., items related categorically such as two or more fruits) were compared using three 
response measures that varied the task demands placed on the preschool children. Young children were capable of using both taxonomic and thematic groupings when presented with minimally demanding tasks. When task demands increased, preschool children reverted to a primarily thematic strategy, and produced more taxonomic strategy errors.

Gentner [12] showed that children do not always make taxonomic inferences, when for example the task is altered and the children are also presented with perceptual choices. Thus, when a perceptual choice was also available, the label condition appeared to increase perceptual over taxonomic choices [13, 17]. In other words, the child's understanding of the question or problem - not the addition of a label compelled children to focus on a non-obvious category.

In a more recent study, Markowitz [23] studied the impact of stimulus manipulability on taxonomic versus thematic preferences using a forced-choice match-to-sample task. Participants in the manipulable condition were given the target item and were told to place it with their choice (among a thematic, taxonomic and irrelevant choice). After a brief pause that allowed participants to consider the choices, the experimenter physically handed the target item to the participant and said, "Look at this. Can you put this with another one?" This ensured tactile, sensorimotor interactions occurred in the manipulable condition. Preschool participants made more thematic choices when the thematic relationship involved a direct, functional interaction than when it did not. Thus, the encouragement of real-world action led to increased thematic classification.

Instructions given in the experimental tasks have also been found to affect children's responses [25, 35, 34]. Different instructions of a task can recruit the use of one strategy over the other. Variation in instructions on a match-to sample task (e.g., "choose the one that goes best" vs. "goes with" vs. "another one" vs. "which is the same kind of thing as this one?") will induce either thematic or taxonomic choices. For example, at three years of age, children seem to choose more taxonomic objects in the "another one" condition, and at four years of age, they choose more thematic alternatives in the "goes best" condition $[10,34]$. The above studies demonstrate that preschoolers do not have a clear preference for one or the other type of categorization when faced with a new word but that their responses can be also affected by the experimenter's instructions.

Therefore, there is research evidence suggesting that preschoolers can selectively attend to complex, meaningful stimuli attributes to make inferences about word meaning which are highly task and context specific. These inferences depend on the task demands (e.g. stimulus variables, linguistic variables, novel words, task demands, instructions, social reinforcement, predicate cues) as well as on child variables - age, motivation, attention- $[8,5,18,23,33,16]$.

Now, turning to the rationale behind the present study, two were the main motives. Firstly, children in their everyday life acquire knowledge from the surrounding world by facing things in meaningful contexts. However, most of the experimental studies usually, assess word learning using artificial paradigms, ignoring the social and linguistic context in which the new words are usually introduced. Secondly, there is a group of studies highlighting the influence of contextual factors on children's inferencing abilities about a word's meaning. Last, a few studies have explored procedural factors (instructions, context of task presentation) affecting preschoolers' inference strategies on identifying a new word referent, using samples from other languages than English. Thus, the overall aim of the current study was to investigate the impact of task presentation and context of exposure on children's response patterns of novel word object pairings. We examined different age groups in order to unfold possible developmental differences in children's response patterns. It was predicted that as children develop they may use different strategies.

\subsection{Design of the Overall Study}

A repeat measures design was employed. We presented children with Markman and Hutchinson's experimental paradigm [21], by having modified the instructions given to the children. In Markman and Hutchinson's study [21] while in the no label condition, the question was "find another one which is the same kind of thing as this one" in the label condition, the question was "find another dax". It was assumed that the instructions used in the label condition in previous studies encouraged children to focus on taxonomic relations, significantly influencing the results. In the present study, the children were given a neutral -ambiguous instruction, "find another " $x$ " that goes best with this one", in order to observe the child's interpretation, and draw a conclusion by assuming that the child's predilections reflected in his/her interpretation. The study included 3 experiments which were administered to the children with a fifteen days gap.

In the first experiment, the classical experimental paradigm by Markman and Hutchinson [21] was employed, using both the label and no label conditions, and providing neutral instructions, in order to test the taxonomic bias. In the label condition the target object was labelled with a novel word, say "an $x$ while in the no label condition the target word was not labelled (see Experiment 1 Sample and Procedure). Experiment 2 further examined the influence of task presentation on children's responses with the same cohort and the same experimental paradigm, but having increased the range of choices available, thereby testing the impact of the number of choices on children's response pattern in comparison to the first experiment. In the third experiment we examined the impact of context of exposure. In other words, the extent in which altering the context of task presentation, introducing a visual story context in which the children encountered the novel words would differentiate their choices irrespective of linguistic input (label, no label conditions) [4]. Particularly, Experiment 3 provided a context to prime children's responses in a more naturalistic 
context. It addressed whether children's choices can be altered by the nature of the pragmatic demands of the task's presentation. The hypothesis of the third experiment was that certain stimuli (e.g. story reading, illustrations) would be more likely to produce thematic responses irrespective of linguistic input (no label, label).

To further explore children's task understanding, the participants were asked to justify their responses across the three experiments. However, the importance of such information which is constrained by the pragmatics of the experimental setting is often underestimated and not examined by most of the experimental studies in the field of word learning [11]. Preschoolers' task understanding can have a substantial impact on their performance [30], although difficult to assess especially to young children. Justifications can provide additional evidence that subjects' choices are not random, because it is expected that justifications will commensurate with their choices [11, 23]. Therefore, by examining children's justifications we aimed to further extend our understanding of the child's cognitive processes task.

\section{Methodology}

\subsection{Experiment 1}

Experiment 1 was carried out in order to investigate the existence of the taxonomic bias, employing the classical experimental paradigm by Markman and Hutchinson [21], employing neutral instructions in comparison to the ones used in Markman's and Hutchinson's study.

\subsubsection{Participants}

Sixty four monolingual preschool children who belonged to two age groups participated in this study. Thirty two of them belonged into the first age group and their age was ranged from 4 to 5 years with a mean age of 4.5 years while thirty two children belonged to the second age group which ranged in age from 5 to 6 years with a mean age of 5.6 years. The children came from middle-class, public Greek preschool settings had no identified learning difficulties and had been balanced for sex.

\subsubsection{Procedure}

The participants were tested individually for approximately $15 \mathrm{~min}$. in a quiet area of their school following the procedure reported in Markman and Hutchinson [21]. All the participants were introduced to a hand puppet that spoke puppet language. Children from each age group were randomly assigned to either label or no label condition. In the label condition, they were presented with a single target picture followed by two other choice pictures. Each child was told: "See this?" (The target picture) "It is a fakoufi" (non-word). Then the experimenter placed the two choice pictures (taxonomic and thematic associate) on the table and asked the child "Find another "fakoufi" that goes best with this one".

An identical procedure was used in the no label condition, except for the instructions given. Thus, each child was told "See this?" (The target picture). Then, the experimenter placed the two choice pictures (taxonomic and thematic associate) on the table and asked the child "Which of these two (pictures of taxonomic and thematic associates) goes best with this one" (the target picture)? After each trial, both in the label and the no label condition, each child was asked to form a brief justification of why those items had been grouped together. Thus, the experimenter asked each child "why does this one (target picture) and this one (child's choice picture) go together?" The researcher did not provide children with any feedback about their answers. All the children participated in both conditions, and the order of conditions was balanced.

\subsubsection{Measures}

Thirty six cards with black and white pictures of common objects were used [20]. All objects were familiar to the children. There were 12 target items. For each target item there were two response pictures, one picture was thematically related to the target and the other taxonomically related (see Appendix 1).

\subsubsection{Results of Experiment 1}

Table 1 presents response type by condition and age group. Analysis of the children's responses demonstrated that both age groups provided more thematic responses across all conditions. The differences were found to be significant for the 5-6 year olds in the no label condition $(\mathrm{z}=-2.74, \mathrm{p}=.05)$ and label condition $(\mathrm{z}=-2.54, \mathrm{p}=.01)$.

Table 1. Number of responses by condition and age group in Experiment 1

\begin{tabular}{ccccc}
\hline Condition & \multicolumn{2}{c}{ Label } & \multicolumn{2}{c}{ No label } \\
\hline Response & Taxonomic & Thematic & Taxonomic & Thematic \\
type & $\mathrm{N} \%$ & $\mathrm{~N} \%$ & $\mathrm{~N} \%$ & $\mathrm{~N} \%$ \\
& & 106 & $87(45.30)$ & 105 \\
4-5 years & $86(44.80)$ & $(55.20)$ & & $(54.70)$ \\
& & 120 & $62(32.30)$ & 130 \\
5- 6 years & $72(37.50 \%)$ & $(62.50)$ & $(67.70)$ \\
\hline
\end{tabular}

\subsubsection{Coding of the Justifications}

Children's justifications for the preferred items were assigned to one of four categories. There were the categorical, the thematic, the other and none justifications. The above categories included the following subcategories: (1) Categorical justifications: they focused on taxonomic relations and included: (1a) super ordinate membership (e.g. "because they are both animals"); (1b) subordinate membership (e.g. "because they are both pets"); (1c) feature membership (e.g. "because they both have big eyes"). (2) Thematic justifications: they focused on a shared, functional, interactive relationship between the target and the choice items. This type of justifications included the following subcategories: (2a) spatiotemporal justification: referred to a situational relation between the target and the choice item (e.g. "because the ant is on the rock"). (2b) functional 
justification: referred to a relationship between the target and the choice items characterized by a verb of action (e.g. "because the dog eats the bone"), or belonging (e.g. "because this is the dog's house"). (3) Other justifications: the target picture and the choice picture were just named (e.g. "because this is a ring and this is a necklace") or the child produced an idiosyncratic association between the items (e.g. "because they are my friends"). (4) None justification: when the child failed to provide any justification. Similar justification categories have been used by other researchers $[11,23]$.

Response protocols for 10 subjects at each age group were independently coded by a second experienced researcher. The interrater reliability (as calculated by an interclass correlation coefficient) was .96 $(\mathrm{p}<.001)$ yielding $95.8 \%$ agreement. Disagreements were resolved by discussion.

The majority of the younger children did not provide a justification for their choices. When they provided a justification this was mainly categorical both in the no label $(75 \%)$ and the label condition $(63 \%)$. The same finding was evident for the 5-6 year olds who also provided mainly categorical justifications for their choices both for the no label (81\%) and the label condition (88\%). So, although they provided more thematic responses, demonstrating their explicit knowledge, they justified them categorically highlighting also their implicit knowledge about the world. The above findings may suggest that, either the children were not clear about the demands of the task, or that the provision of justifications is a more complex cognitive task that may reflect different levels of understanding.

\subsubsection{Discussion of Experiment 1}

Experiment 1 failed to identify a taxonomic constraint since the children provided more thematic than taxonomic responses across both conditions (no label, label). No evidence was found of the different response patterns, Markman and Hutchinson, [21] proposed between the no label and label condition, since no effect of label on children's responses was found. A possible explanation could be that past research has used a more taxonomic oriented question eliciting from children more taxonomic choices. For example, Markman and Hutchinson [21], in the label condition asked the children: "See this? It's a fep. Can you find another one that is the same kind of thing as this fep?" In contrast, in the presents study, the instructions (task presentation) were modified to be more neutral, without guiding children's inferences about the new words. Also, restricting the number of items to two as in Experiment 1 might have been very restricting about the types of relations children would look for. Therefore, Experiment 2 was designed in order to examine the influence of task presentation, and particularly, the impact of number of choices in the response set on children's response pattern.

\subsection{Experiment 2}

Experiment 2 further examined the influence of task presentation and context of exposure on children's responses with the same cohort of children, but having increased the range of choices available thereby testing whether task presentation (in terms of number of choices) can scaffold children's response pattern in comparison to the first experiment.

\subsubsection{Participants}

The same sample of children as before participated also in Experiment 2. Children from each age group were randomly assigned to either label or no label condition.

\subsubsection{Procedure}

The procedure of Experiment 2 was identical with that of Experiment 1, except that the number of choice-pictures provided to the children increased from two (that were used in Experiment 1) to four pictures. Thus, children had to choose not between one taxonomic and one thematic associate, but between two taxonomic and two thematic associates (Appendix 2). All the children were tested individually on 8 items in a quiet area of their school.

Again, as in Experiment 1, after each trial, children were asked to provide a justification of their response. Justifications for their choices were again coded into four categories (categorical, thematic, other don't know). Response protocols for 10 subjects at each age group were independently coded by a second coder. The interrater reliability (as calculated by an interclass correlation coefficient) was $.95(\mathrm{p}<.001)$ yielding $94.8 \%$ agreement. Disagreements were resolved by discussion.

\subsubsection{Measures}

Forty cards with black and white pictures of common objects were used. Eight of the pictures served as target pictures. Each target picture could be associated with four other choice pictures - two taxonomic and two thematic associates - (see Appendix 2). The stimuli had been previously normed for their relatedness both to adults and children.

\subsubsection{Results of Experiment 2}

Table 2 present response type by condition and age group. Analysis of the children's responses demonstrated that in Experiment 2, both age groups provided significantly more taxonomic responses across conditions, however, the differences were not significant.

Table 2. Number of responses by condition and age group in Experiment 2

\begin{tabular}{ccccc}
\hline Condition & \multicolumn{2}{c}{ Label } & \multicolumn{2}{c}{ No label } \\
\hline Response & Taxonomic & Thematic & Taxonomic & Thematic \\
type & $\mathrm{N} \%$ & $\mathrm{~N} \%$ & $\mathrm{~N} \%$ & $\mathrm{~N} \%$ \\
4-5 years & $79(61.70)$ & $49(38.30)$ & $80(62.50)$ & $48(37.50)$ \\
5- 6 years & $70(54.70 \%)$ & $58(45.30)$ & $70(54.70)$ & $58(45.30)$ \\
\hline
\end{tabular}

Children's justifications of their responses in Experiment 2 were also analyzed. The younger children (4-5 year old children) failed to provide justifications for their responses both in the no label (53\%) and the label condition (40\%). 
When they provided a justification this was mainly categorical both in the no label (36\%) and the label condition (48\%). The same finding was evident for the 5-6 year olds who also provided mainly categorical justifications for their choices both for the no label (41\%) and the label condition $(62 \%)$.

\subsubsection{Discussion of Experiment 2}

At a first glance, it seems that Experiment 2 led children to provide more taxonomic responses and justify them accordingly. However, the high number of "don't know" justifications demonstrated that the provision of justifications is a more complex cognitive task that may reflect different levels of understanding. The results of Experiment 2 provide converging evidence that the likelihood of choosing a taxonomic associate can be increased by simply giving them an addition to the set. As such, children are responding to an experimental constraint and not a cognitive constraint.

\subsection{Experiment 3}

Experiment 3 provided a more naturalistic context of presentation. It addressed whether children's choices can be altered by the nature of the pragmatic demands of the task's presentation. The hypothesis of the third experiment was that certain stimuli (e.g. story reading, illustrations) would be more likely to produce thematic responses irrespective of linguistic input (no label, label).

\subsubsection{Participants}

The same cohort of children as in the previous experiments participated in Experiment 3.

\subsubsection{Procedure}

All the children were allocated to one of four conditions: (a) no label-naming condition, (b) no label-story condition, (c) label-naming condition, (d) label-story condition. In the no label-naming condition the experimenter using a hand-puppet said "I am going to show you a big picture. I will first name the objects in the picture". For each of the five big story scenery pictures, the experimenter named the objects in the following way like in the example (for picture 1: "this is Doris", "this is a pig", "this is a cow", this is a stable", "and this is a fence"). Then, the experimenter said: I'll show you a picture (target picture) and you'll have to find another one that go best with this one (pointing to the target picture).

In the no label-story condition, the experimenter using the same hand-puppet said: "I am going to show you a new big picture. "I will first tell you a story about it. An example of the story is given below for picture 1. "Once upon a time, in a big farm, a pig, a cow and Doris lived. Doris, was very happy about the new stable and the new fence that Mr Babis made for him. He wouldn't feel cold any more during the cold nights of winter and he could run all the day around the field during the spring". Then the experimenter said: I'll show you another picture (target picture) and you'll have to find another one (among these four choice pictures) that goes best with this one" (pointing to the target picture).

In the label-naming condition, the procedure was identical to those of the no label-naming condition, up to the naming of the objects in the picture. Then the experimenter using the hand puppet said "see this (the target picture? It is a "fakoufi". Then the experimenter placed the four choice pictures in front of the child and said to him/her to "Find another "fakoufi" that goes best with this one". Five meaningless 2 or 3 syllable words were used. The words were assigned randomly to the pictures for each child.

The label-story condition was exactly the same like the no label-story condition till the story part. Then the experimenter said: "See this? It is a "fakoufi" (pointing to the target picture). Find another "fakoufi" (among these four choice pictures) that goes best with this one" (pointing to the target picture).

\subsubsection{Measures}

Five big black and white pictures of the story scenery, as well as twenty-five pictures of common objects were used. Five of the pictures served as targets. Each target picture could be associated with four choice pictures - two were taxonomically and two were thematically related to the target picture - (see Appendix 3).

\subsubsection{Results of Experiment 3}

Table 3 presents children's responses in Experiment 3 by condition in each age group. In general terms, both age groups provided more thematic responses irrespective of condition (label naming/label story, no label naming / no label story). The differences were found to be significant for the 5-6 year olds both in the no label-story condition $(\mathrm{z}=-2.42, \mathrm{p}=.01)$ and label-story condition $(\mathrm{z}=-2.54, \mathrm{p}=.01)$.

Table 3. Number of responses by condition and age group in Experiment 3

\begin{tabular}{|c|c|c|c|c|c|c|c|c|}
\hline \multirow{2}{*}{$\begin{array}{c}\text { Condition } \\
\begin{array}{c}\text { Response } \\
\text { type }\end{array}\end{array}$} & \multicolumn{2}{|l|}{ Label-Naming } & \multicolumn{2}{|c|}{ Label-Story } & \multicolumn{2}{|c|}{ No label-Naming } & \multicolumn{2}{|l|}{$\begin{array}{c}\text { No } \\
\text { label-Story }\end{array}$} \\
\hline & $\begin{array}{c}\text { Taxonomic } \\
\mathrm{N} \%\end{array}$ & $\begin{array}{c}\text { Thematic } \\
\mathrm{N} \%\end{array}$ & $\begin{array}{c}\text { Taxonomic } \\
\mathrm{N} \%\end{array}$ & $\begin{array}{c}\text { Thematic } \\
\mathrm{N} \%\end{array}$ & $\begin{array}{c}\text { Taxonomic } \\
\mathrm{N} \%\end{array}$ & $\begin{array}{c}\text { Thematic } \\
\mathrm{N} \%\end{array}$ & $\begin{array}{c}\text { Taxonomic } \\
\mathrm{N} \%\end{array}$ & $\begin{array}{c}\text { Thematic } \\
\mathrm{N} \%\end{array}$ \\
\hline $4-5$ years & $17(42.50)$ & $23(57.50)$ & $18(40)$ & $24(60)$ & $20(50)$ & $20(50)$ & $16(40)$ & $24(60)$ \\
\hline 5- 6 years & $24(60)$ & $16(40)$ & $8(20)$ & $58(45.30)$ & $17(42.5)$ & $23(57.50)$ & $7(17.5)$ & $33(82.50)$ \\
\hline
\end{tabular}


In order to further analyze the possible effects of no label (naming/story) /label (naming/story) condition and age on children's taxonomic responses, a 2 X 2 factorial design with 1 covariate was carried out. No covariate effect of age was observed. Also, no significant differences between no label/label conditions were found. Last, there was no interaction for no label/label and naming/story conditions. However, a marginal significant effect was observed for the naming/story conditions $F(1,59)=3.990, p<0.05$, partial $\eta^{2}$ $=0.06$ ). Thus, overall children provided more thematic than taxonomic responses in the no label/label story conditions than in the no label/label naming conditions (Table 4).

Table 4. Children's taxonomic responses (Means, Std. Errors) in no label/label naming and no label/label story conditions for Experiment 3

\begin{tabular}{lcccc}
\hline & M & S E & $\begin{array}{c}\text { Lower } \\
\text { Bound }\end{array}$ & $\begin{array}{c}\text { Upper } \\
\text { Bound }\end{array}$ \\
\hline No label/label Naming & 2.38 & .27 & 1.82 & 2.94 \\
No label/ label Story & 1.58 & .27 & 1.02 & 2.14 \\
\hline
\end{tabular}

The analysis of children's justifications demonstrated that the majority of 4-5 year old children could not justify their responses (label-naming condition: 21 "don't know" responses out of 40, 53\%; label-story condition: 31 "don't know" responses out of 40, 77\%; no label-naming condition: 31 "don't know" responses out of $4077 \%$ ). When justifications were provided these were mainly categorical both in the label-naming condition: (15 categorical responses and 4 thematic responses) and the label-story condition: (6 categorical responses, and 3 thematic responses). On the other hand in the no label-naming and no label-story condition they provided more thematic than categorical responses in comparison to the label-naming and label-story conditions (no label-naming condition: 8 thematic and only 2 categorical responses, no label-story condition: 6 thematic and 8 categorical responses).

The response rate for the justifications provided was quite different for the 5-6 years old. Particularly, they provided very few "don't know" responses across the 4 conditions and in some cases no "don't know" responses at all, in comparison with the response rate of the younger age group. The same pattern of responses was evident for the 5-6 year olds who also provided mainly categorical justifications for their choices. Regarding their categorical responses, they provided more categorical than thematic responses across the 4 conditions (no label-naming 18 categorical and 7 thematic responses, no label-story condition: 23 categorical and 11 thematic responses, no label-naming condition: 18 categorical and 6 thematic responses, no label-story condition: 30 taxonomic and 5 thematic responses).

\subsubsection{Discussion of Experiment 3}

Experiment 3 examined whether children's choices can be altered by the nature of the pragmatic demands of the task's presentation. The results of Experiment 3 demonstrated that both age groups provided more thematic than taxonomic responses in the no label/label story conditions than in the no label/label naming conditions. Again, the youngest age group of children found more difficult to provide justifications in comparison to the 5-6 year olds. More categorical justifications were given in the label-naming or naming-story conditions, while more thematic justifications were provided in the no label-naming, and no label-story conditions. Experiment 3 confirmed the hypothesis that certain stimuli (e.g. story reading, illustrations) would be more likely to produce thematic responses irrespective of linguistic input (no label, label).

\section{Comparison of Children's Responses Pattern among the Three Experiments}

In order to further explore whether children's response pattern differed across the three experiments a repeated measures MANOVA with two covariates (age and condition) was carried out (Table 5). The analysis demonstrated that there was no covariate effect of age and there was no difference between children's taxonomic responses in the no label and label condition. Multivariate effects were not significant. For these effects Wilks' $\Lambda$ was .92. However, the within subjects effect for repeated measures indicated a significant difference of taxonomic responses, $F(1,122)=$ 2.693, $\mathrm{p}<.05$, (partial $\eta^{2}=.04$ ). The polynomial contrasts revealed a significant linear effect, $F(1,61)=5.068, \mathrm{p}<.05$, (partial $\left.\eta^{2}=.07\right)$. Paired wise comparisons across repeated measures (through Bonferroni adjustment) revealed differences between the Experiment 3 and the other two Experiments. In other words, the mean number of taxonomic responses was smaller in Experiment 3 in comparison with the other two Experiments.

Table 5. Children's taxonomic responses across the three experiments

\begin{tabular}{llll}
\hline & $\mathrm{N}$ & $\mathrm{M}$ & $\mathrm{SD}$ \\
\hline Experiment 1 & 64 & 4.80 & 2.93 \\
Experiment 2 & 64 & 4.67 & 2.55 \\
Experiment 3 & 64 & 1.98 & 1.59 \\
\hline
\end{tabular}

\section{Overall Discussion of the Study}

The focus of the present study was to investigate the impact of task presentation and context of exposure on children's response pattern of novel word object pairings. As it was evident, task presentation and context of exposure can provide significant information in helping children to establish a referent $[22,32]$ than do children's preferences for certain feature over others during labeling as Markman and Hutchsinson [21] argued.

Particularly, the first experiment, failed to replicate the taxonomic constraint/bias in the label condition when neutral instructions were given to the children. Results in 
Experiment 1 failed to replicate Markman's and Hutchinson's [21] taxonomic constraint when one parameter of the task presentation (task instructions) was changed to more neutral instructions. Children provided more taxonomic responses than thematic across ages and irrespective of label/no label conditions.

However, in the second Experiment, when another parameter was modified, the context of presentation of the stimuli, by extending the range of options (provision of more choices in the response set) children were led to a significant increase in taxonomic responses, again without a label and age effect. Last, the story context, in the third experiment, made children in the no label and label story conditions to shift their attention to thematic rather than to taxonomic choices compared to no label and label naming conditions, despite having the increased range of choices that led to taxonomic responding in Experiment 2. The above findings of all the three experiments demonstrate no evidence of a taxonomic constraint.

Analysis of children's justifications revealed a different pattern of responding across the three experiments demonstrating children's sensitivity to the contextual factors of the task, in other words on how they interpret tasks and task specific instructions $[10,5]$. The majority of the younger children did not provide a justification for their choices. Both age groups provided more "categorical" than "thematic" justifications for their taxonomic choices in both conditions (label and no label) across the first two experiments irrespective of age. Similarly, in Experiment 3 most of the children in the younger age group could not justify their responses across conditions, while the older children found easier to justify their pairings. However, the modification of the context of presentation in Experiment 3 and particularly during the no label-naming and no label-story condition shifted the response rate of the justifications given by the 4-5 year old children into providing more thematic than categorical justifications in comparison to the label-naming and label-story conditions

Young children might be able to associate pictures in ways that look like they are using taxonomic representations to do so, but their overt behavior may not be supported by underlying stable taxonomic representations [2]. Similarly, in Greenfield's and Scott's study [14] the 3-year-olds could explain most of their thematically paired items but very few of their taxonomically paired items. Also, in Lucarriello, Kyratzis and Nelson study [20], when young children were asked to explain different matches, they tended to offer event-based explanations for their taxonomic pairings. The above findings can be explained by the hypothesis that preschool children can cross classify items depending on the task requirements and context of presentation [24, 23, 33].

Last, the across experiments comparison revealed a significant drop of taxonomic responses in Experiment 3 comparing with Experiment 1 and 2. The current findings suggest that preschoolers were quite sensitive to specific task constraints and capable of taking into account the contextual demands in order to figure out what a new word means [19].The impact of task presentation and context of exposure which was found in the present study confirms other studies showing that young children's ability to utilize the thematic and taxonomic knowledge might depend on response alternatives [36].

\section{Conclusions}

The present study demonstrated that there is no evidence to support the presence of an inflexible constraint, in that case, informed only by the presence or absence of a novel label. The findings agree with relevant studies [23, 33] suggesting that taxonomic and thematic relations are available to children, and it is the context of presentation that recruits one strategy over the other [24, 33, 23].

Children's variant performance across the experiments demonstrated that in each experimental situation the children used or interpreted differently the context in which the information was presented, story or no story, and the scope for responding in two items versus four. The context of experiment itself might have made one kind of relation more salient than others as it was observed in the present study. The data further reveal the importance of social pragmatic information in helping learners to pick out the meanings of the new words $[23,32,31]$.

Therefore, children's selections between taxonomic and thematic stimuli were multiply determined as well as highly task and context specific. More specifically, as it has been claimed by a group of researchers[8, 16], the effect of lexical input alone is fragile dependent on (a) child's cognitive capacities (e.g. memory, attention, conceptual knowledge) (b) his/her age, (c) previous experience with the testing items, (d) the linguistic regularities of the task (phonological, syntactic, semantic, and pragmatic regularities) and (e) task demands.

We hope that the present study can contribute to the existing literature both theoretically and methodologically. Theoretically, the current research demonstrated the fragility of the so-called constraints (with data from a non-English speaking population) turning the focus of the research agenda, from the learning mechanisms to the learning context that can also support word learning. The current data also raise methodological questions about the design of experimental tasks and the possible conclusions that can be drawn from them, about children's inferencing abilities. As such, the procedure of word learning should be seen under the influence of perceptual, cognitive, linguistic, social, and $[27,9]$. Both, researchers and educators should consider word learning assessment taking place in more real life situations [26].

Nevertheless, some recommendations for future work would be to include in the participants more age groups belonging at different levels of language development (children with developmental delays, SLI) in order to further investigate the ongoing language acquisition process. Also, future research could examine children's justifications for 
the non-preferred items, providing more clarification for children's choices.

\section{Acknowledgements}

I am very grateful to Prof. Julie Dockrell for all her constant support and constructive comments during this research.

\section{Appendices}

\section{Appendix 1}

\section{Stimulus Items for Experiment 1}

\begin{tabular}{ccc}
\hline Target object & Taxonomic choice & Thematic choice \\
\hline Cow & Pig & Milk \\
Ring & Hand & Hand \\
Door & Window & Key \\
Crib & Adult bed & Baby \\
Bee & Ant & Flower \\
Hanger & Hook & Dress \\
Cup & Glass & Tea pot \\
Car & Bicycle & Car tire \\
Sprinkler & Wat. Can & Grass \\
Paintbrush & Crayons & Easel \\
Train & Bus & Track \\
\hline Dog & Cat & Bone \\
\hline
\end{tabular}

\section{Appendix 2}

Stimulus Items for Experiment 2

\begin{tabular}{|c|c|c|c|c|}
\hline $\begin{array}{c}\text { Taxonomic } \\
\text { object }\end{array}$ & $\begin{array}{c}\text { Taxonomic } \\
\text { choice } 1\end{array}$ & $\begin{array}{c}\text { Taxonomic } \\
\text { choice } 2\end{array}$ & $\begin{array}{l}\text { Thematic } \\
\text { choice } 1\end{array}$ & $\begin{array}{c}\text { Thematic } \\
\text { choice } 2\end{array}$ \\
\hline Note & Coins & Gold coins & Wallet & Trunk \\
\hline Guitar & Drum & Trumpet & Notes & Maestro \\
\hline Spoon & Fork & Knife & $\begin{array}{c}\text { Double } \\
\text { plate }\end{array}$ & Plate \\
\hline Dog & Goat & Cow & $\begin{array}{l}\text { Dog's } \\
\text { house }\end{array}$ & Leash \\
\hline Eagle & Pigeon & Parrot & Nest & Tree \\
\hline $\begin{array}{l}\text { Spoon of } \\
\text { medicine }\end{array}$ & Capsule & Medicine & Child & Nurse \\
\hline Comb & Brush & Small comb & Woman & Desk \\
\hline Glasses & $\begin{array}{c}\text { Water } \\
\text { glasses }\end{array}$ & Binocular & Face & Case \\
\hline
\end{tabular}

\section{Appendix 3}

Stimulus Items for Experiment 3

\begin{tabular}{ccccc}
\hline $\begin{array}{c}\text { Target } \\
\text { object }\end{array}$ & $\begin{array}{c}\text { Taxonomic } \\
\text { choice } 1\end{array}$ & $\begin{array}{c}\text { Taxonomic } \\
\text { choice } 2\end{array}$ & $\begin{array}{c}\text { Thematic } \\
\text { choice } 1\end{array}$ & $\begin{array}{c}\text { Thematic } \\
\text { choice 2 }\end{array}$ \\
\hline Horse & Cow & Pig & Stable & Fence \\
Ant & Bee & Spider & Bread & Rock \\
Snowshoes & Sticks & Boots & Boy & Snow \\
Duck & Wolf & Horse & House & Pool \\
\hline Mouse & Frog & Sheep & House & Wood \\
\hline
\end{tabular}

\section{REFERENCES}

[1] N. Blanchet, P. J. Dunham, F. Dunham. Differences in preschool children's conceptual strategies when thinking about animate entities and artifacts. Developmental Psychology, vol. 37, 791- 800, 2001.

[2] A. Blaye, V. B. Peyron, J. L. Paour. Categorical flexibility in children: Distinguishing response flexibility from conceptual flexibility; the protracted development of taxonomic representations. European Journal of Developmental Psychology, vol. 3, $163-188,2006$.

[3] L. Bloom. Language acquisition in its developmental context. In D. Kuhn \& R. Siegler (Eds.), The Handbook of child psychology: vol. 2, Cognition, perception, and language. New York: Wiley. 1997

[4] T. Cameron - Faulkner, E. Lieven, M. Tomasello. A construction based analysis of child directed speech. Cognitive Science, vol. 27, 843-873, 2003.

[5] G. O. Deák, S. D. Ray, A. D. Pick. Effects of age, reminders, and task difficulty on young children's rule-switching flexibility, Cognitive Development 19, 385-400, 2004.

[6] G. O. Dea'k. The development of cognitive flexibility and language abilities. In R. Kail (Eds.), Advances in Child Development and Behavior, vol. 31, 271-327. San Diego: Academic Press, 2003.

[7] G. O. Dea'k, S.D. Ray, A.D. Pick. Matching and naming objects by shape or function: Age and context effects in Preschool children. Developmental Psychology, 38, 503-518, 2002.

[8] G. O. Dea'k. The growth of flexible problem-solving: How children infer word meanings using semantic context. Journal of Cognition and Development, vol. 1, 157-191, 2000.

[9] G. O. Dea'k. Hunting the Fox of word learning: Why "constraints" fail to capture it. Developmental Review, vol. 20, 29-80, 2000.

[10] G. Dea'k, P. J. Bauer. The dynamics of preschoolers' categorization choices. Child Development, vol. 67, 740-767, 1996. 
[11] G. Dea'k, P. J. Bauer. The effects of task comprehension on preschoolers' and adults' categorization choices. Journal of Experimental Child Psychology, vol. 60, 393-427, 1995.

[12] D. Gentner. The development of relational category knowledge. In L. Gershkoff-Stowe \& D. H. Rakison, (Eds.), Building object categories in developmental time. (pp. 245-275). Hillsdale, NJ: Erlbaum, 2005.

[13] R. M. Golinkoff, M. Shuff-Bailey, R. Olguin, W. Ruan. Young children extend novel words at the basic level: Evidence for the principle of categorical scope. Developmental Psychology, vol. 31, 494-507. 1995.

[14] D. B. Greenfield, M. S. Scott. Young children's preference for complementary pairs: Evidence against a shift to taxonomic preference. Developmental Psychology, vol. 22, 19-21, 1986.

[15] T. M. Gurekis, B, C. Love Common mechanisms in infant and adult category learning. Infancy, vol. 5, 173-198, 2004.

[16] D. Honomichl, Z. Chen. Relations as rules: The role of attention in the Dimensional change card sort task. Developmental Psychology, vol. 47, 50-60, 2011.

[17] M. Imai, D, Gentner, N. Uchida. Children's theories of word meaning: The role of shape similarity in early acquisition. Cognitive development, vol. 9, 45-75, 1994.

[18] M. Imai, D. Gentner. A cross-linguistic study of early word meaning: Universal ontology and linguistic influence. Cognition, 62, 169-200, 1997.

[19] T. Ionescu. I can put it there too. Flexible object categorization in preschool children and the factors that can act upon it. Cognition, Brain, Behavior, vol. 11, 809-829, 2007.

[20] J. Lucariello A. Kyratzis K. Nelson. Taxonomic knowledge: What kind and when? Child Development, 63, 978-998, 1992.

[21] E. M. Markman, J. E. Hutchinson. Children's sensitivity to constraints on word learning: Taxonomic versus thematic relations. Cognitive Psychology, vol. 16, 1-27, 1984.

[22] E. M. Markman, G. F. Wachtel. Children's use of mutual exclusivity to constrain the meanings of words. Cognitive Psychology, vol. 20, 121-157, 1988.

[23] A. Markowitz. Factors that affect taxonomic versus thematic preferences in children and adults: The role of manipulability. Unpublished thesis, University of Michigan, 2010.

[24] S. P. Nguyen, G. L. Murphy. An Apple is More Than Just a
Fruit: Cross-Classification in Children's Concepts. Child Development, vol. 74, 1783-180, 2003.

[25] J. G., Osborne, D. O. Calhoun. Themes, taxons, and trial types in children's matching to sample: methodological considerations. Journal of Experimental Child Psychology, vol. $68,35-50,1998$.

[26] A.M. Ralli, J. Dockrell. Real word learning: Exploring the development of children's lexical representations, Psychology, vol. 17, 1-24, 2010.

[27] A. M. Ralli, J.E. Dockrell, Multiple measures of assessing vocabulary acquisition: implication for understanding lexical development, Psychology, vol. 5, 587-603, 2005.

[28] M. S. Scott, D. B. Greenfield, R. C. Urbano. A Comparison of Complementary and Taxonomic Utilization: Significance of the Dependent Measure. International Journal of Behavioral Development, vol. 8, 241-256, 1985.

[29] M. Shatz. Bootstrapping Operations in Child Language. In K. E. Nelson and A. Van Kleeck (Eds.), Children's Language, vol. 6, (pp. 1-22). Hillsdale, NJ: Erlbaum, 1987.

[30] M. Siegal. Knowing children. Experiments in conversation and cognition. Hillsdale, NJ: Erlbaum, 1991.

[31] M. Tomasello, M. J. Farrar. Joint attention and early language. Child Development, 57, 1454-1463, 1986.

[32] M. Tomasello, M. Barton. Learning words in non-ostensive context. Developmental Psychology, vol. 30, 639-650, 1995.

[33] E. A., Ware, S. A., Gelman, F. Kleinberg. Pictures and objects evoke distinct conceptual relations. Unpublished manuscript, Department of Psychology, University of Michigan, Ann Arbor, Michigan, 2009.

[34] S.R. Waxman, L.L. Nagy. Challenging the notion of a thematic preference in young children. Developmental Psychology, vol. 33, 555-567,1997.

[35] S.R., Waxman, T. D. Kosowski. Nouns mark category relations: toddlers' and preschoolers' word-learning biases. Child Development, vol. 61, 1461-1473, 1990.

[36] R. Yukawa, Y. Sakata. Preschool children's knowledge of thematic and taxonomic relations. Paper presented at the $14^{\text {th }}$ Biennial Meeting of ISSBD, Quebec, 1996.

[37] D. Zhang. Learn a word learning constraint: Emergence of the taxonomic constraint and its relationship with word learning acquisition, unpublished thesis, University of Bamberg, 2007. 